\title{
Thermal degradation of polythiophene- natural rubber and polythiophene-synthetic rubber conducting polymer composites
}

\author{
Jale Hacaloğlu*, Semih Yiğit, Ural Akbulut and Levent Toppare $\nmid$ \\ Department of Chemistry, Middle East Technical University, 06531 Ankara, Turkey \\ (Revised 12 December 1996)
}

\begin{abstract}
Thermal degradation of conducting polymer composites of polythiophene and rubbers was studied by direct and indirect pyrolysis mass spectrometry techniques. The samples were prepared by electrooxidation of polythiophene using natural rubber or synthetic rubber as the insulating matrix. Presence of decomposition products which were not observed during pyrolysis of pure polythiophene and rubbers, and disappearance of rubber-based pyrolysis mass peaks, together with changes in thermal stability and behaviour, may directly be related to a chemical interaction between the components of the composites. The pyrolysis data were used to propose possible polymerization and degradation mechanisms. (C) 1997 Elsevier Science Ltd.
\end{abstract}

(Keywords: conducting polymers; polythiophene-rubber composites; pyrolysis)

\section{INTRODUCTION}

Synthesis of conducting polymers has attracted great attention, owing to their possible applications as electronic materials, gas sensors, electromagnetic shielding coatings, etc. Several studies on the preparation of conducting polymers like polypyrrole, polythiophene and their derivatives revealed that these materials are electrically conductive, though poor in mechanical properties ${ }^{1-4}$. Homogeneous composites using an insulating polymer matrix became one of the major solutions in the synthesis of conducting polymers with better physical and mechanical properties 5,6 . Furthermore, some studies revealed that there may exist a chemical interaction between the pyrrole oligomer and the insulating polymers during the electrochemical synthesis ${ }^{7}$.
Although several spectrometric methods proved to be useful in distinguishing the resultant electrolytic film from the mechanically mixed polymers, pyrolysis mass spectrometry has become a powerful tool for that purpose. Pyrolysis techniques and their applications to polymer degradation studies have been discussed in a number of recent publications ${ }^{8-10}$.

In this work thermal behaviour of polythiophenenatural rubber and polythiophene--synthetic rubber electrolytic films, prepared by electrooxidation of thiophene onto natural rubber or synthetic rubber coated electrodes, were studied by recording mass spectra as a function of temperature under both direct and indirect pyrolysis m.s. conditions. The change in thermal stability was investigated by comparing the thermal behaviour of composites with that of pure homopolymers.

Table 1 Relative intensities and the assigned chemical formulas of the most intense and/or characteristic fragments observed in the direct pyrolysis mass spectra of PTh/NR, PTh/SR, PTh, NR and SR at temperatures corresponding to maximum product yield

\begin{tabular}{|c|c|c|c|c|c|c|}
\hline \multirow[b]{2}{*}{$m / z$} & \multicolumn{5}{|c|}{ Relative intensity } & \multirow[b]{2}{*}{ Assignment } \\
\hline & $\mathrm{PTh} / \mathrm{NR}$ & $\mathrm{PTh} / \mathrm{SR}$ & PTh & NR & SR & \\
\hline 44 & 1000 & 1000 & 1000 & 206 & 190 & $\mathrm{CS}$ \\
\hline 57 & 215 & 268 & 151 & 103 & 106 & $\mathrm{C}_{4} \mathrm{H}_{9}$ \\
\hline 68 & 112 & 86 & - & 710 & 629 & Isoprene \\
\hline 81 & 89 & 80 & 5 & 1000 & 1000 & $\mathrm{C}_{5} \mathrm{H}_{7} \mathrm{CH}_{2}$ \\
\hline 84 & 135 & 144 & 115 & - & - & Thiophene \\
\hline 95 & 91 & 74 & 5 & 647 & 673 & $\mathrm{C}_{6} \mathrm{H}_{9} \mathrm{CH}_{2}$ \\
\hline 136 & - & - & 72 & 319 & 384 & Isoprene dimer \\
\hline 168 & 21 & 15 & 38 & - & - & Thiophene dimer \\
\hline 174 & 86 & 23 & - & - & - & $\mathrm{CH}_{2} \mathrm{C}\left(\mathrm{CH}_{3}\right) \mathrm{C}=\mathrm{S}:=\mathrm{CH}-\mathrm{C}=\mathrm{C}$ \\
\hline 204 & - & - & - & 60 & 78 & Isoprene trimer \\
\hline 272 & - & - & - & 14 & 20 & Isoprene tetramer \\
\hline
\end{tabular}

* To whom correspondence should be addressed

$\dagger$ Present address: Bilkent University, Dept. Chem. 06533, Ankara,

Turkey 


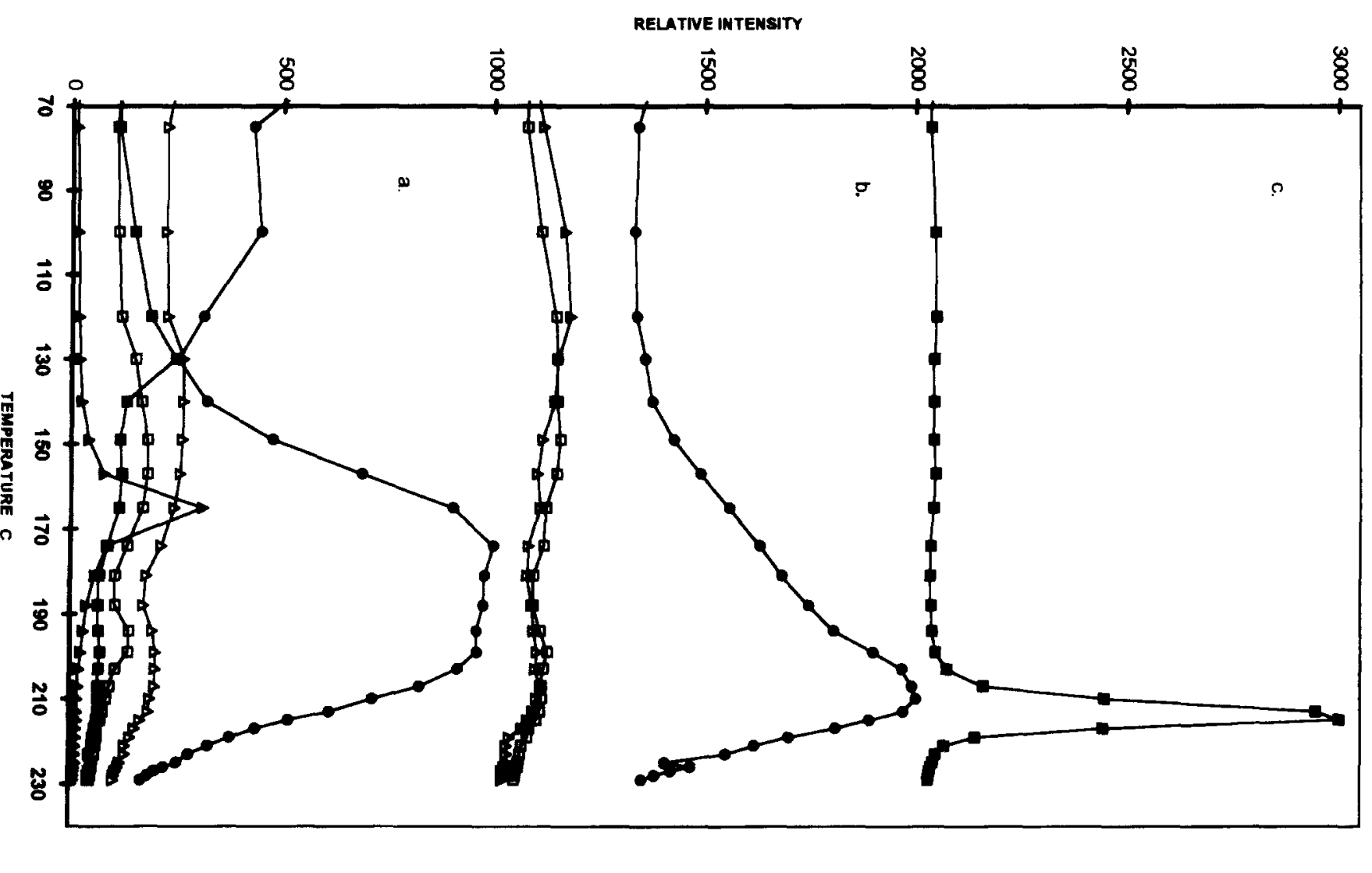

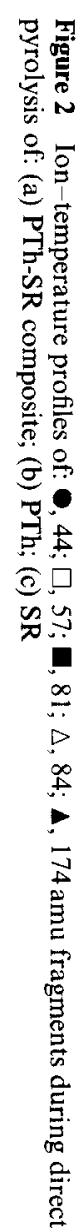

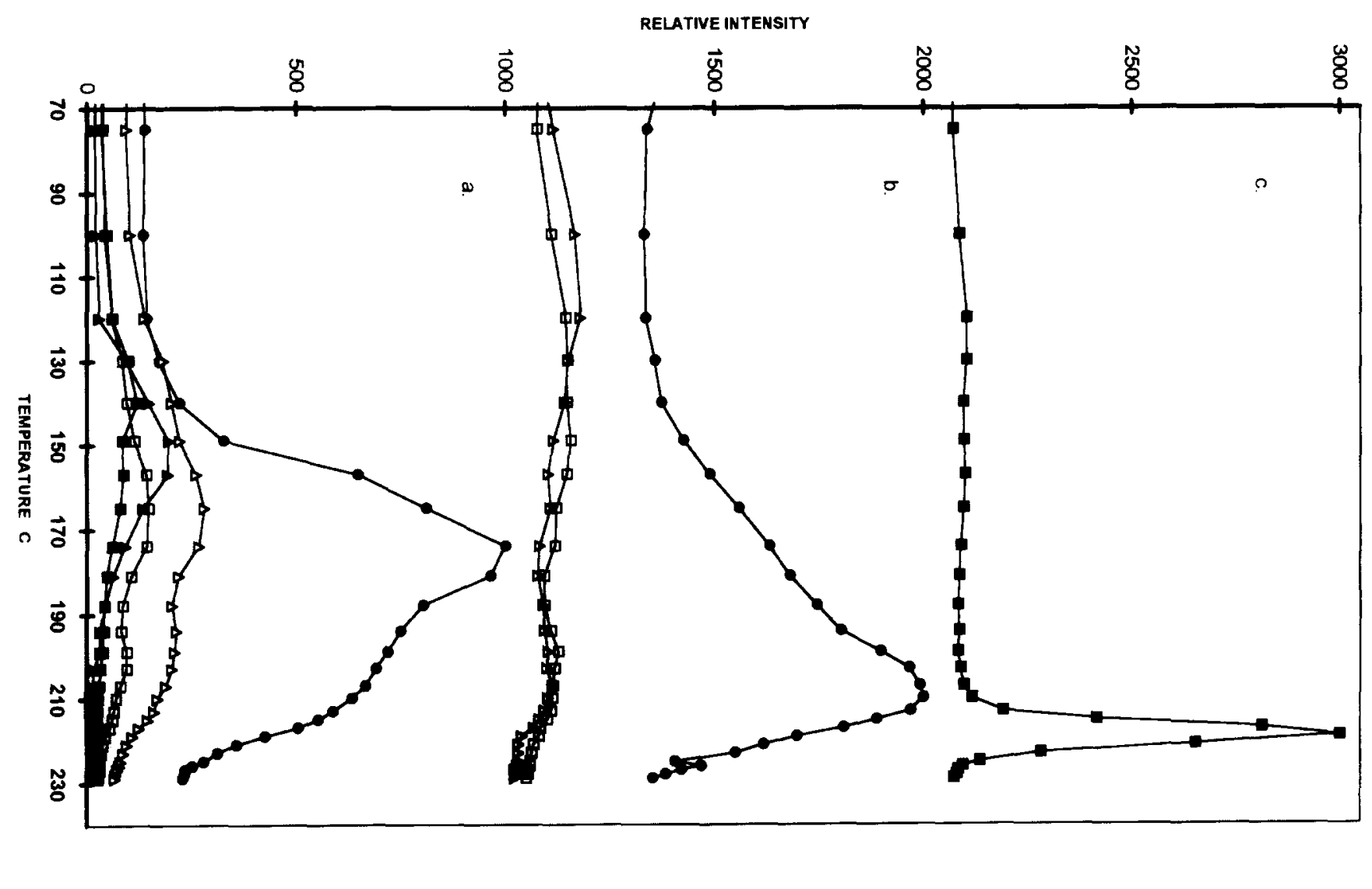

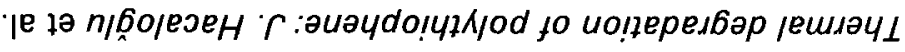




\section{EXPERIMENTAL}

Polythiophene-natural rubber (PTh-NR) and polythiophene-synthetic rubber (PTh-SR) composites were prepared by electrooxidation of polythiophene onto a natural or synthetic rubber coated platinum electrode at a constant potential of $+1.8 \mathrm{~V}$ vs $\mathrm{Ag}^{+}\left(10^{-2} \mathrm{moll}^{-1}\right)$ reference electrode using a Wenking POS 73 potenstiostat. The details of the electrochemical synthesis were given in an earlier report ${ }^{8}$.

Direct pyrolysis m.s. equipment simply consists of a direct insertion pyrolysis probe (stainless steel tube silver soldered to a copper sample holder assemble), its control unit designed in our laboratories, a Balzers QMG 311 quadruple m.s. and a personal computer for the control of the instrument and data acquisition and processing. Fine powder polymer samples $(0.1 \mathrm{mg})$ were heated rapidly to $120^{\circ} \mathrm{C}$, and then the heating rate was kept constant at $2^{\circ} \mathrm{C} \mathrm{min}^{-1}$ during the direct pyrolysis experiments. The details of the system were discussed in our previous studies ${ }^{11,12}$.

In the case of evolved gas analysis (indirect pyrolysis) by MS, the same system with a pyrolysis chamber instead of the pyrolysis probe was applied. A needle valve is used to control the flow of the evolved gases into the m.s. Samples of $1.0 \mathrm{mg}$ were used in indirect pyrolysis experiments. The heating rate was $10^{\circ} \mathrm{C} \mathrm{min}^{-1}$.

\section{RESULTS AND DISCUSSION}

\section{Direct pyrolysis}

Thermal decomposition of natural rubber (NR), synthetic rubber (SR) and polythiophene have been investigated under direct pyrolysis conditions in our previous studies ${ }^{8}$. NR and SR showed very identical thermal behaviour, in accordance with other thermal analysis data. Degradation mainly occurred in a narrow temperature range of 213 to $225^{\circ} \mathrm{C}$, yielding principally 1 -methylcyclopentene and 1-methylcyclohexene by $\alpha, \beta$ cleavages followed by cyclization reactions. Monomers and low mass oligomers were among the high yield decomposition products.

Under the same conditions, polythiophene decomposed by evolution of low molecular weight species at considerably low temperature ranges. Degradation yield increased steadily, and reached its maximum value around $220^{\circ} \mathrm{C}$. The data indicated unsaturation along the chain, and the breaking of the thiophene ring was assigned to be the most possible decomposition pathway.

The most intense and/or characteristic fragments observed in the pyrolysis MS of PTh/NR and PTh/SR composites recorded at $173^{\circ} \mathrm{C}$ (corresponding to maximum decomposition yield temperature) are given in Table 1. The diagnostic ions produced during pyrolysis of pure NR, SR and PTh are also included for comparison. Two points that should be noted immediately are the shift of decomposition temperature to lower ranges and disappearance of NR and SR based peaks in the case of composites. Furthermore, new peaks that were not observed for pure NR, SR and PTh are also present. To get a better understanding of the iontemperature profiles (variation of intensities as a function<smiles>CCC(C)(C)C1C=CC[IH]1</smiles>

temperature) of some selected fragments, peaks at 44, 57, 81,84 and $174 \mathrm{amu}$ observed during direct pyrolysis of PTh-NR and PTh-SR are plotted in Figures 1 and 2 respectively. The ion-temperature profiles of related peaks from pure homopolymers, 44, 57, 84 amu peaks from PTh and $81 \mathrm{amu}$ peak from SR and NR are also included for comparison.

The trends in the ion-temperature profiles, namely the two maxima at 173 and $195^{\circ} \mathrm{C}$ may indicate the presence of units with different thermal stabilities along the polymer chain. Actually the lack of NR- and SR-based peaks may be directly related to the decomposition of these polymers during electrooxidative polymerization of polythiophene, while presence of fragments that were absent in pyrolysis m.s. of related homopolymers NR, SR and PTh may be regarded as evidence of a chemical interaction between the components of the composites. Possible mechanisms that explain these experimental results may be elucidated by the attack of thiophene to the double bond as follows:

Two possible products are:

I.

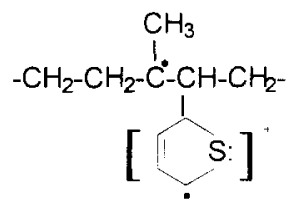

II.<smiles>C=C(C)C(C)(CCC)C1CCCC1</smiles>

Then the following paths may be proposed: From product I two different structures may be produced:

Ia.<smiles>CCC(C)C(C)C1C=CC(C)[Te]1</smiles>

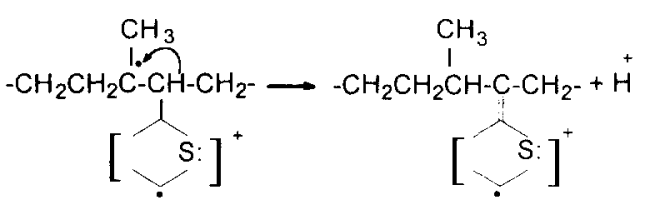

Ib.

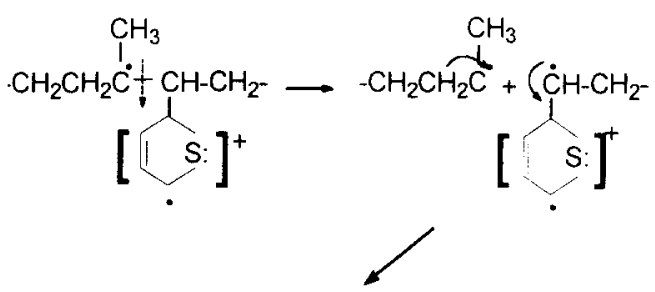<smiles>C=CC=CC=CC=[PH2+]</smiles> 
From structure II the following mechanism may be proposed:

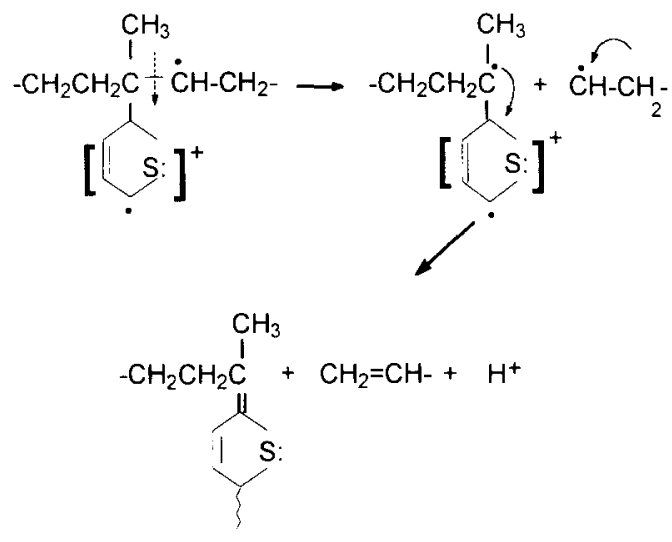

Although the reaction pathway given by scheme $\mathrm{Ib}$ explains the decomposition of rubbers during electrooxidative polymerization of thiophene, the final product cannot yield the 57 and $174 \mathrm{amu}$ peaks that were observed during thermal degradation. Thus, structure II which explains both decomposition during polymerization and the new characteristic thermal degradation product at $174 \mathrm{amu}$ seems to be the main polymerization product. The following mechanism for the formation of $174 \mathrm{amu}$ fragment may be produced:
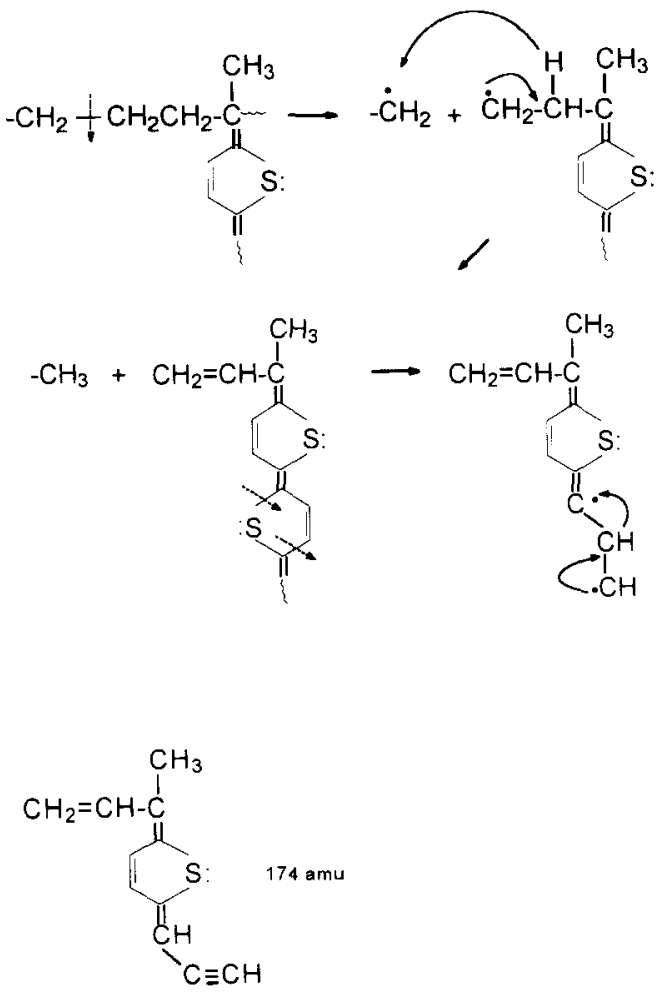

However, the presence of the intense 57 amu peak may be better related to the thermal decomposition of polymer as indicated by mechanism Ia; i.e. cleavage at $\alpha$ carbon followed by $\mathrm{H}$-abstraction reactions, as indicated:

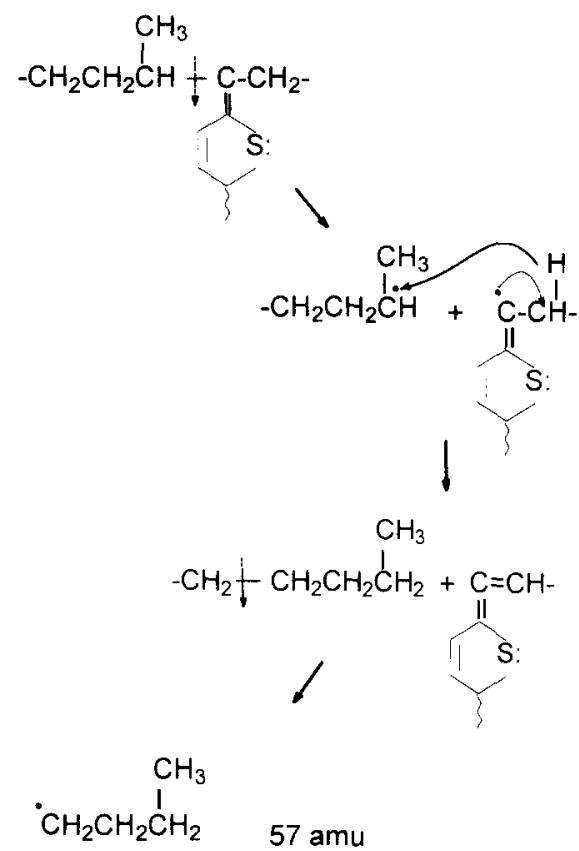

Thus, one may conclude that structure Ia is also produced during polymerization as a byproduct.

\section{Indirect pyrolysis}

Indirect pyrolysis analyses indicated quite similar thermal behaviour for NR and SR. Evolution of small molecular weight species, mainly monomer and 1-methyl cyclopentene, started to appear in the pyrolysis MS above $350^{\circ} \mathrm{C}$. Maximum decomposition yield was observed at $450^{\circ} \mathrm{C}$. Thermal degradation of PTh started at very low temperatures and decomposition yield reached its maximum value around $220^{\circ} \mathrm{C}$. Main degradation products were the monomer, $\mathrm{HCS}, \mathrm{S}_{2}$ and small molecular weight hydrocarbons. $\mathrm{H}_{2} \mathrm{~S}$ formation was observed around $300^{\circ} \mathrm{C}$ and it was the main product above $400^{\circ} \mathrm{C}^{8}$.

Indirect pyrolysis analysis of PTh/NR and PTh/SR showed very similar thermal behaviour, as in the case of direct pyrolysis results. The intense and/or characteristic decomposition products are summarized in Table 2. Data related to NR, SR and PTh are also included for comparison. The low temperature decomposition yielding $\mathrm{HCS}, \mathrm{S}_{2}$ and small molecular weight hydrocarbons resembling those observed for PTh. However, an intense $57 \mathrm{amu}$ peak above $230^{\circ} \mathrm{C}$, which was absent or very weak in the indirect pyrolysis m.s. of NR, SR and PTh, may be regarded as further support for the proposal of a presence of chemical interaction between the components of the composites. Furthermore, the intensities of the characteristic peaks of NR and SR not only decreased considerably but also started to appear in the spectra of the composites at lower temperatures compared to pure homopolymers NR and SR. To clarify the indirect pyrolysis findings, ion-temperature profiles of fragments at 34, 44,57 and $67 \mathrm{amu}$ are plotted in Figures 3 and 4 . It is clear from the figures that $\mathrm{H}_{2} \mathrm{~S}$ formation from the composites occurred more readily, as the $\mathrm{H}_{2} \mathrm{~S}$ peak appeared in the pyrolysis $\mathrm{MS}$ around $200^{\circ} \mathrm{C}$.

A similar trend to that observed for the indirect pyrolysis of polyamide-polythiophene composites ${ }^{9}$ was 

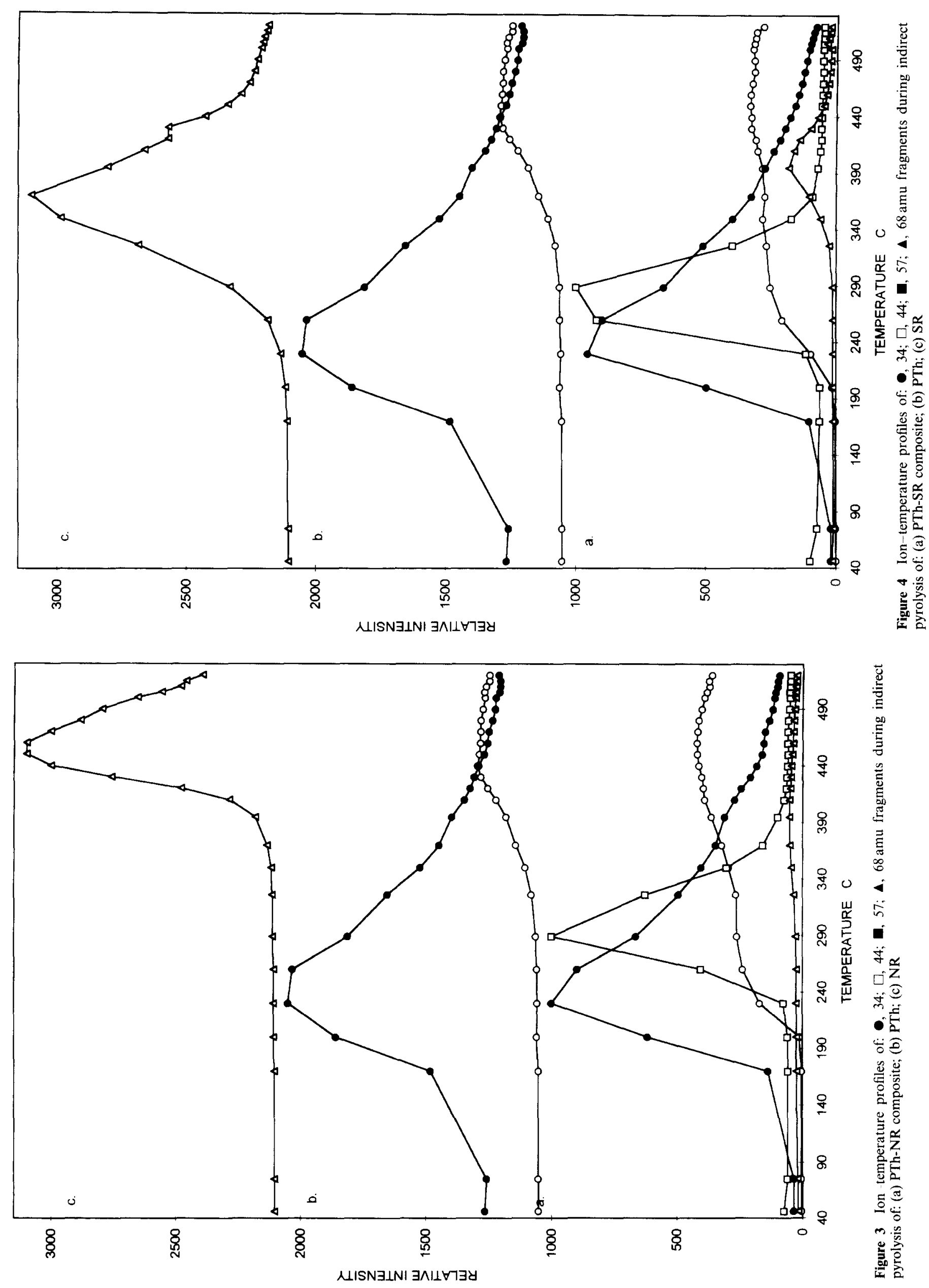
Table 2 Relative intensities and the assigned chemical formulas of the most intense and/or characteristic fragments observed in the indirect pyrolysis mass spectra of PTh/NR, PTh/SR, PTh, NR and SR at temperatures corresponding to maximum product yield

\begin{tabular}{|c|c|c|c|c|c|c|}
\hline \multirow[b]{2}{*}{$m / z$} & \multicolumn{5}{|c|}{ Relative intensity } & \multirow[b]{2}{*}{ Assignment } \\
\hline & $\mathrm{PTh} / \mathrm{NR}$ & $\mathrm{PTh} / \mathrm{SR}$ & PTh & $\mathrm{NR}$ & SR & \\
\hline 34 & 126 & 115 & 7 & - & - & $\mathrm{H}_{2} \mathrm{~S}$ \\
\hline 44 & 663 & 799 & 1000 & - & - & $\mathrm{CS}$ \\
\hline 57 & 1000 & 1000 & 10 & 21 & 17 & $\mathrm{C}_{4} \mathrm{H}_{9}$ \\
\hline 64 & 102 & 123 & 149 & - & - & $\mathrm{S}_{2}$ \\
\hline 67 & 26 & 29 & 35 & 1000 & 1000 & $\mathrm{C}_{5} \mathrm{H}_{7}$ \\
\hline 84 & 32 & 34 & 234 & - & - & Monomer \\
\hline
\end{tabular}

not seen for polyamide-polythiophene mechanical mixtures, and the relatively low temperature production of $\mathrm{H}_{2} \mathrm{~S}$ from the composites was proposed to be due to the direct evolution of $\mathrm{H}_{2} \mathrm{~S}$. Parallel experiments with mechanical mixtures of PTh and rubbers could not be done, as attempts for the preparation of homogeneous mixtures failed. Yet, the significant changes in the iontemperature profiles of composite based peaks with respect to the corresponding homopolymers may be directly related to a chemical interaction between the components of the composites. These results confirm the suggested polymer structure and decomposition mechanism.

\section{CONCLUSION}

The pyrolysis m.s. studies of conducting polymer composites of polythiophene-rubbers revealed that a chemical interaction between the components of the composites formed during the electrochemical polymerization of thiophene. It was also determined that thermal characteristics of rubbers were totally disappeared in the composites indicating degradation of the rubbers during the electrooxidative polymerization.

\section{ACKNOWLEDGEMENTS}

This work is partially supported by TUBITAK Research Funds TBAG-Ay/28 and TBAG- 1422.

\section{REFERENCES}

1. Lindenberger, H., Schafer-Sielbert, D., Roth, S. and Hanack, H., Synth. Met., 1987, 18, 37.

2. Ojio, T., Qui, J. and Shen, D., Synth. Met., 1987, 18, 183.

3. Man, T., Motobe, T. and Whang, Y. E., Miyata, Synth. Met., $1991,45,26$.

4. Quian, R., Qui, J. and Shen, D., Synth. Met., 1987, 18, 13.

5. DePaoli, M., Panero, S., Prosperi, P. and Scrosati, B., Electrochim. Acta, 1981, 129, 115.

6. Wang, H. L. and Fernandez, J. E., Macromolecules, 1993, 26, 336.

7. Wang, H. L., Toppare, L. and Fernandez, J. E., Macromolecules, 1990, 23, 1053.

8. Yiğit, S., Hacaloğlu, J., Akbulut, U. and Toppare, L., Synth. Met., 1996, 79, 11 .

9. Vatansever, F., Akbulut, U., Toppare, L. and Hacaloğlu, J., Polymer, 1996, 37, 1103.

10. Selampinar, F., Toppare, L., Akbulut, U., Yalcin, T. and Süzer, S., Synth. Met., 1995, 68, 109.

11. Fares, M. M., Yalçin, T., Hacaloğlu, J., Güngör, A. and Süzer, S., Analyst, 1994, 119, 693.

12. Hacaloğlu, J. and Önal, A., Europ. Polym. J., 1995, 31, 103. 